\title{
ASPERGILLUS PAKISTANICUS: MICROSCOPIC AND PHYLOGENETIC ANALYSIS OF A NEW ENTOMOPATHOGENIC FUNGI ISOLATED FROM THE SOIL OF THE CHANGA MANGA FOREST, PAKISTAN
}

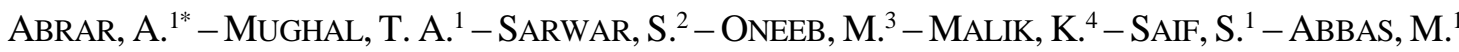 \\ ${ }^{I}$ Department of Environmental Science, Lahore College for Women University, Lahore, Pakistan \\ ${ }^{2}$ Department of Botany, Lahore College for Women University, Lahore, Pakistan \\ ${ }^{3}$ Department of Parasitology, University of Veterinary and Animal Sciences, Lahore, Pakistan \\ ${ }^{4}$ Center for Excellence in Molecular Biology, University of The Punjab, Lahore, Pakistan \\ *Corresponding author \\ e-mail: amina.abrar@outlook.com \\ (Received 22 $2^{\text {nd }}$ Aug 2019; accepted $3^{\text {rd }}$ Feb 2020)
}

\begin{abstract}
Changa Manga forest is a man-made forest in Pakistan. The soil properties of this forest serve an ideal habitat for a vast variety of entomopathogenic fungi. A number of entomopathogenic fungi were isolated from the soil samples collected from the Changa Manga Forest using Galleria bait method during this investigation. Among these isolated fungi, Aspergillus pakistanicus was found to be morphologically and phylogenetically different from closely related Aspergillus species thus described as a new species. The fungal species was identified on the basis of colony morphology; light microscopy; scanning electron microscopy and by molecular analysis. Macroscopic and microscopic comparison with other species of the respective genus along with sequencing of $18 \mathrm{~S}$ rRNA genes confirmed its uniqueness and supports its recognition as a novel species. Its angular ornamented conidia and separate clade in the phylogenetic tree support it as a new taxa. A detailed description, microscopic images, and comparison with morphologically and phylogenetically similar species are presented.
\end{abstract}

Keywords: ascomycetes, insect bait, Indomalaya ecozone, taxonomy, $18 \mathrm{~S} r R N A$

\section{Introduction}

Fertile soil of forests and agricultural lands provide natural habitats for the entomopathogenic fungi. Soil type and geographical location are important contributory factors to mark out the occurence of these fungi (Meyling and Eilenberg, 2007). Terrestrial planes of Punjab, Pakistan support a rich diversity of soil born entomopathogenic fungi (Wakil et al., 2014). Changa Manga forest is situated in the district of Kasur near Lahore, Pakistan with the total area of 5063 ha. According to WWF classification it is located in the Indomalaya ecozone. The fertile soil of the Changa Manga forest supports many plant species. The pH (7.7 to 8.0) and other properties of the soil in the Changa Manga forest provide ideal habitat for soil associated entomopathogenic fungi. The Changa Manga forest is the home of many mammals, birds, reptiles, amphibians and insects. Common floral biota comprise of Morus alba, Dalbergia sissoo, Acacia nilotica, Populus and Eucalyptus species (Ahmad, 2017).

For the recovery of entomopathogenic fungi, Tenebrio molitor or Galleria mellonella are usually added to soil samples as insect bait (Ali-Shtayeh et al., 2003; Abrar et al., 2019). Entomopathogenic fungi presents a broad array of ecologically, morphologically 
and phylogenetically diverse fungal species belonging to Ascomycetes and Zygomycetes (Araujo and Hughes, 2016). Aspergillus species are widespread in the environment. Species of genus Aspergillus belong to the group having many important functions in natural ecosystems and also proved to be beneficial for human economy. These fungi are usually found associated with the plant litter and soil of many terrestrial habitats (Bennett, 2010). The genus Aspergillus with diverse group of species can adapt to a broad range of environmental conditions including humidity and temperature (Cray et al., 2013). Asexual conidia produced by Aspergillus species are stress tolerant and also produce highly persistent sexual ascospores for reproduction supporting widespread distribution of these species (Krijgsheld et al., 2013). A number of species of Aspergillus are strong pathogens of insects and used as biocontrol agents against many insect vectors (Nnakumusana, 1985; Lage-de-Moraes et al., 2001; Yang et al., 2015; Zhang et al., 2015; Bawin et al., 2016; Kaur et al., 2019). During the present study a new entomopathogenic Aspergillus species has been isolated from the Changa Manga forest of Pakistan.

\section{Materials and methods}

\section{Fungal isolation}

The local strains of entomopathogenic fungi were isolated from the soil of the Changa Manga Forest, Pakistan located $80 \mathrm{~km}$ south west of Lahore at $31^{\circ} 05^{\prime} \mathrm{N} 73^{\circ} 58^{\prime} \mathrm{E}$ in the district of Kasur (Fig. 1). The isolation was carried out after the moon soon period in September-October, 2017. The isolation of fungi was done by employing insect bait method (Meyling and Eilenberg, 2006). Forth instars of Galleria Mellonella were used as bait insects. PDA media was used for the mass culturing of the local fungal isolates at $25^{\circ} \mathrm{C}$ for seven days to obtain fungal colonies on plates (Abreu et al., 2003).

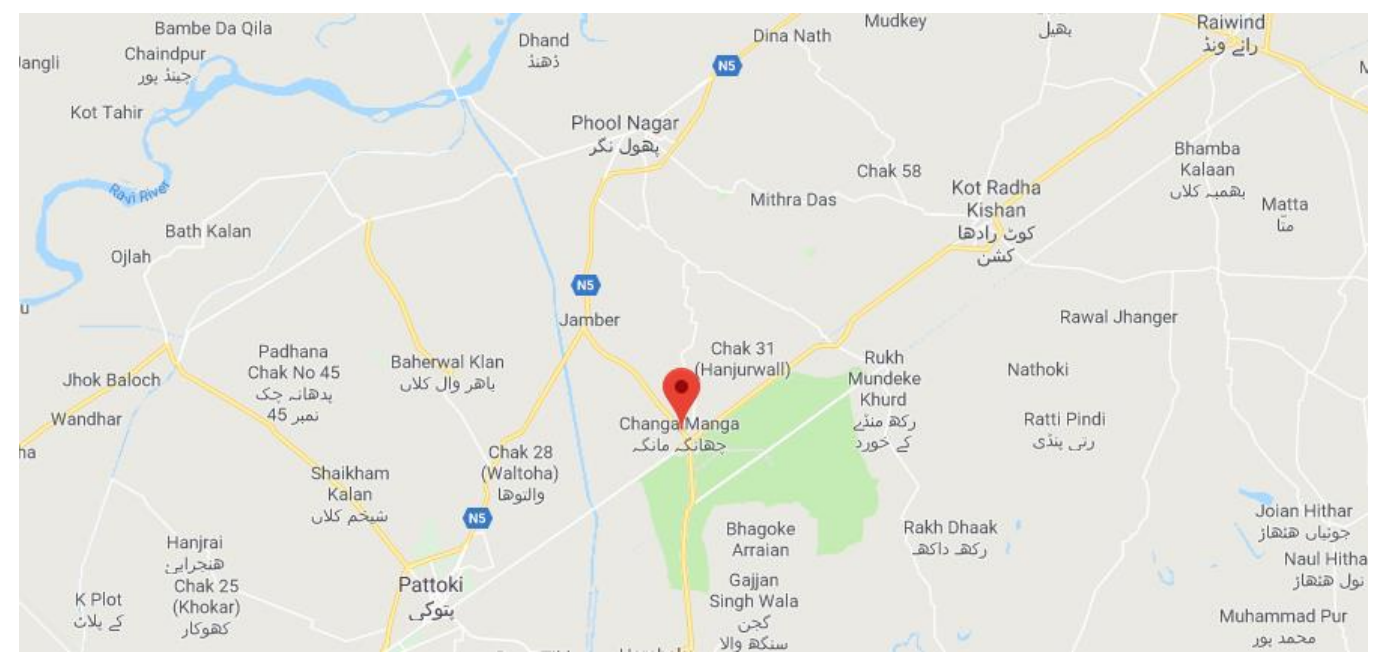

Figure 1. Map showing sampling site Changa Manga forest, Kausar, Pakistan. (Source: www.googleearth.com accessed on 13-06-2017)

\section{Macroscopic and microscopic examination}

The fungi were identified on the basis of colony morphology, vegetative and reproductive structures using taxonomic key (Klich, 2002; Bennet, 2010; Varga et al., 2011; Afzal et al., 2013). Morphological characteristics studied for the identification of 
species were color and shape of the fungal colony, margins and growth rate. Microscopic characteristics were studied under 100X magnification of Nikon E-200 Trinocular Microscope equipped with DS-Fi 1-L2 camera system (Japan). The characteristics regarding hyphae, vesicle, metula, phalides, conidiophore and conidia were observed.

\section{Scanning electron microscopic examination}

The SEM technique was carried out at the Electron Microscope Unit of the Central Research Laboratory, LCWU, Lahore by using standard protocol. Spores ornamentations were photographed.

\section{Molecular and phylogenetic analyses}

Molecular analysis was done to confirm the identification of isolated entomopathogenic fungi. DNA was extracted by following the method described by Devarajan and Kim (2018) and specific PCR assays were carried by employing primers NS1 5' (GTA GTC ATA TGC TTG TCT C) 3' and NS8 5' (TCC GCA GGT TCA CCT ACG GA) 3' (Embley et al., 1992). Ultra Clean PCR Clean-up DNA Purification kit (MoBio, USA) was used to clean the specific PCR products. The PCR purified products were directly sequenced for $18 \mathrm{~S}$ rRNA region by the company Macrogen (Seoul, Korea).

Consensus sequence was subjected to BLAST analysis at NCBI. Sequences which showed maximum similarity were retrieved from the GenBank and aligned by Muscle Alignment Tool (Edgar, 2004). Phylogenetic analysis was carried out with maximum likelihood criterion using MEGA5 software following algorithm and Jukes and Cantor (1969) model of the sequences evolution (Tamura et al., 2011) and 1000 bootstrap values. The sequence was deposited in GenBank.

\section{Results}

\section{Holotype}

Aspergillus pakistanicus Abrar, Mughal \& Sarwar sp. nov. (Fig. 2) MycoBank No.: MB 830877.

Pakistan, Punjab Province: Lahore District, Changa Manga Forest, 24 September 2017, AA100717; GenBank MK371711.

\section{Description}

Colony: dark green with yellow undersurface; Colony reverse: mustered brown; Texture: powdery; Margins: entire: Growth rate: rapid; Hyphae: branched septate; Conidiophore: smooth, 100-250 $\mu \mathrm{m}$ in length, 4-5 $\mu \mathrm{m}$ in diameter; Conidial head: compact and densely columnar; Conidia: irregular to angular, spiny, about $3 \mu \mathrm{m}$ in diameter; Vesicles: globose to hemispherical, biseriate; Metula: long ampuliform; Phialides: long ampuliform; Thermo tolerant species with optimal growth temperature $30-40{ }^{\circ} \mathrm{C}$.

\section{Key features}

Colony color dark green with yellow undersurface, long ampuliform metula and phalides, angular and spiny conidia. 


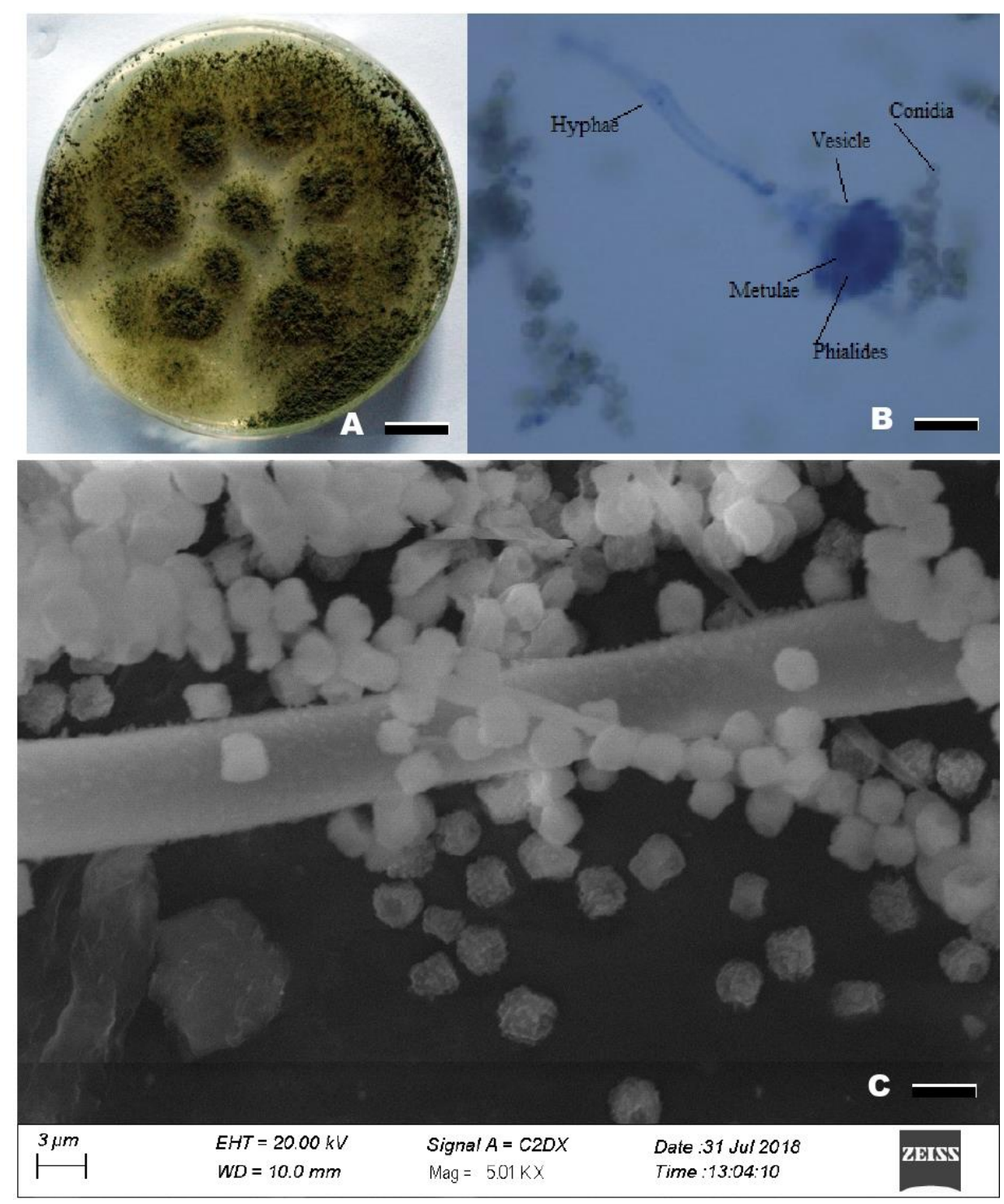

Figure 2. (A-C) Aspergillus pakistanicus. (A) Macroscopic features of colony; (B) Microscopic features by LM showing vesicle, conidia, conidiophore, phalides, metula and hyphae. (C) SEM micrograph of conidia highlighting their shape, ornamentation and size. Bars for $A \& B=1.5$ $\mathrm{cm}$, for $C=2 \mu \mathrm{m}$

\section{Etymology}

It was based on locality as it was isolated from a forest of Pakistan.

\section{Distribution}

It was found in the soil of the Changa Manga forest, Kasur District, Punjab Province, Pakistan.

\section{Material examined}

Aspergillus pakistanicus Abrar, Mughal \& Sarwar: Pakistan, forest soil of Changa Manga, 24 September 2017, AA100717; GenBank MK371711. 


\section{Molecular phylogeny}

During BLAST analysis sequences showed maximum similarity (less than cut off 97\% value) with related species of genus Aspergillus. Phylogenetic analyses were based on data set of 31 sequences including the sequences from Pakistan. MUSCLE alignment tool was used to align all sequences. After editing and trimming, phylogenetic analysis was done by MEGA5 using maximum likelihood criterion. There were 1787 characters in final data set including 1022 conserved, 702 variable and 616 parsimony informative sites. In the resulting consensus phylogram, the sequence generated during this study form separate clade showing distinct identity (Fig. 3).

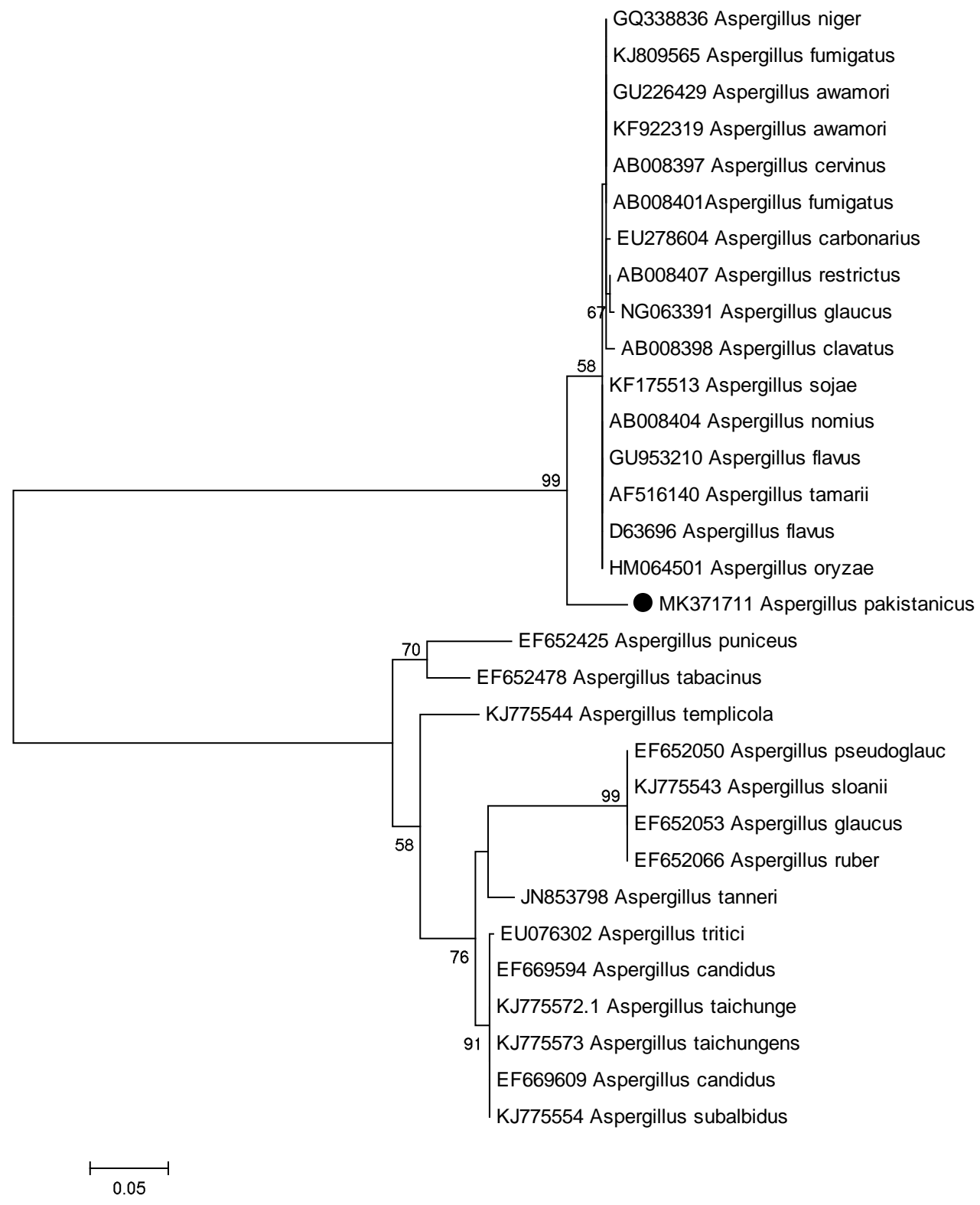

Figure 3. Phylogenetic position of Aspergillus pakistanicus with other Aspergillus spp. Tree inferred by maximum likelihood analysis. The numbers against branches indicate the percentage (>50\%) at which a given branch was supported in 1000 bootstrap replications. GenBank accession number are given at the end of species names. $\bullet$ indicates species reported from Pakistan 


\section{Discussion}

The present research was based on the morphological and molecular identification of entomopathogenic fungus belonging to the genus Aspergillus. The species was isolated from the Changa Manga Forest, Pakistan. Identification of many Aspergillus species remain challenging because of the variability in phenotypic characteristics of genetically distinct species (Samson et al., 2006). In recent years, with the help of phylogenetic analyses, various new species belonging to the genus Aspergillus have been identified (Guinea et al., 2015).

A number of Aspergillus species were isolated during the present study including Aspergillus terreus, Aspergillus parasiticus, Aspergillus niger, Aspergillus oryzae and a novel Aspergillus species (Fig. 4). Morphological characteristics of various entomopathogenic Aspergillus species isolated during the study were observed on PDA media (Table 1).

Table 1. Macroscopic and microscopic characteristics of entomopathogenic Aspergillus species isolated from the Changa Manga forest, Pakistan.

\begin{tabular}{|c|c|c|}
\hline Fungal isolate & Macroscopic morphology & Microscopic morphology \\
\hline $\begin{array}{l}\text { Aspergillus } \\
\text { parasiticus }\end{array}$ & $\begin{array}{l}\text { Colony color dark green, growth } \\
\text { moderate to rapid, margins entire, } \\
\text { texture powdery }\end{array}$ & $\begin{array}{l}\text { Hyphae branched septate, conidiophore } \\
\text { short, } 400 \text { to } 500 \mu \mathrm{m} \text { in length, vesicles } \\
\text { small averaging } 30 \mu \mathrm{m} \text { in size to which the } \\
\text { phialides are directly attached and conidia } \\
\text { rough thick walls and spherical in shape }\end{array}$ \\
\hline Aspergillus terreus & $\begin{array}{l}\text { Colony brownish in color when } \\
\text { observed after } 3^{\text {rd }} \text { day of incubation and } \\
\text { gets darker like cinnamon-brown } \\
\text { colony coloration observed after 7-8 } \\
\text { days, growth rapid, margins entire, } \\
\text { texture velvety }\end{array}$ & $\begin{array}{c}\text { Hyphae branched septate, conidiophore } \\
\text { smooth, } 100-250 \mu \mathrm{m} \text { in length, } 4-6 \mu \mathrm{m} \text { in } \\
\text { diameter, vesicles globose with cylindrical } \\
\text { metulae and phialides, conidia globose- } \\
\text { shaped and smooth-walled and about } 2 \mu \mathrm{m} \\
\text { in diameter }\end{array}$ \\
\hline Aspergillus niger & $\begin{array}{l}\text { Colony starts with pale yellow color } \\
\text { and gets dark brown to black quickly, } \\
\text { growth very rapid, margins entire, } \\
\text { texture powdery }\end{array}$ & $\begin{array}{l}\text { Hyphae branched septate, conidiophore } \\
\text { unbranched, double walled and smooth, } \\
200 \text { to } 400 \mu \mathrm{m} \text { in length, } 7 \text { to } 10 \mu \mathrm{m} \text { in } \\
\text { diameter, vesicles globose, conidial head } \\
\text { blackish brown, split with age, conidia } \\
\text { round and } 2.5-4 \mu \mathrm{m} \text { in diameter }\end{array}$ \\
\hline Aspergillus oryzae & $\begin{array}{l}\text { Colony color grayish green to olive } \\
\text { green, growth moderate to rapid, } \\
\text { margins entire, texture velvety }\end{array}$ & $\begin{array}{l}\text { Hyphae branched septate, conidiophore } \\
\text { smooth, } 400 \text { to } 700 \mu \mathrm{m} \text { in length, } 22 \text { to } 25 \\
\mu \mathrm{m} \text { in diameter, vesicles globose with short } \\
\text { metulae and elongated cylindrical phialides, } \\
\text { conidia with smooth walls and about } 4 \text { to } 6 \\
\mu \mathrm{m} \text { in diameter }\end{array}$ \\
\hline $\begin{array}{l}\text { Aspergillus } \\
\text { pakistanicus }\end{array}$ & $\begin{array}{l}\text { Colony light yellow in color initially } \\
\text { and then dark green with light yellow } \\
\text { undersurface, margins entire; growth } \\
\text { rate rapid; texture powdery }\end{array}$ & $\begin{array}{l}\text { Hyphae branched septate; conidiophore } \\
\text { smooth, } 100-250 \mu \mathrm{m} \text { in length, } 4-5 \mu \mathrm{m} \text { in } \\
\text { diameter; conidial head compact and } \\
\text { densely columnar; conidia irregular to } \\
\text { angular, spiny, about } 3 \mu \mathrm{m} \text { in diameter; } \\
\text { vesicles globose to hemispherical, biseriate; } \\
\text { metula long ampuliform; phialides long } \\
\text { ampuliform }\end{array}$ \\
\hline
\end{tabular}




$$
-3801 \text { - }
$$

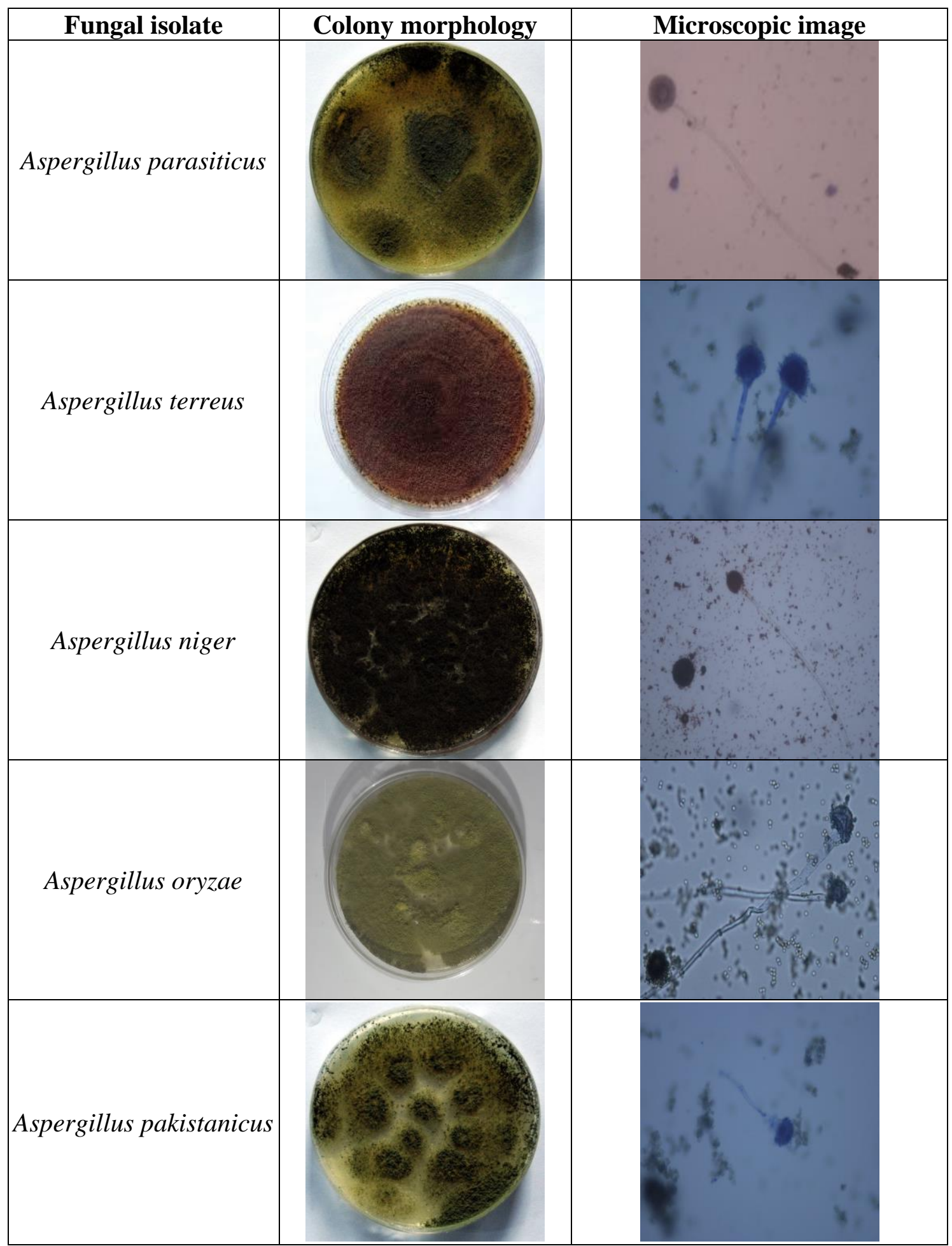

Figure 4. Colony morphology on PDA and microscopic images of entomopathogenic Aspergillus species isolated form Changa Manga forest, Pakistan

Detailed morphological analyses of the new species revealed that A. pakistanicus closely resembles $A$. oryzae but have some distinguished macroscopic and microscopic characteristics. Specifically, A. pakistanicus have dark green colony colour due to 
pigmentation of the vegetative mycelium with light yellow undersurface and powdery texture while A. sojae have white to grayish green to olive green colony colour with velvety texture as reported in many studies (Matsuura and Miyazima,1993; Haack et al., 2006; Ye et al., 2014). Both A. pakistanicus and A. oryzae have biseriate vesicle and produce asexual conidia that are also known as phialidic conidia found at the end of conidiophores. Conidia of $A$. oryzae have smooth surface (Haack et al., 2006) while the new species have rough surfaced angular conidia. Genetically A. pakistanicus matches closely with A. oryzae but less matching value than standard BLAST (less than 97\% identity) and well differentiated position in phylogenetic tree showed this species as new.

\section{Conclusion}

Entomopathogenic Aspergillus pakistanicus is regarded as novel species, based on the morphological characteristics and genetic distinction with well differentiated position in the phylogenetic tree reported during the present investigation. Further studies can be conducted to evaluate the entomopathogenic efficacy of Aspergillus pakistanicus against insects to explore its insecticidal potential.

\section{REFERENCES}

[1] Abrar, A., Mughal, T. A., Oneeb, M., Tahir, E., Khalid, S., Malik, K. (2019): Persistence of local strain of entomopathogenic fungi Aspergillus flavus in indoor air. - International Journal of Bioscience 14(3): 133-139.

[2] Abreu, J., Gonzalez, J., Jaqueman, F. (2003): Conservación por liofilación de diferentes especies de géneros de levaduras. - Alimentaria 40: 119-122.

[3] Afzal, H., Shazad, S., Qamar, S., Nisa, S. Q. U. (2013): Morphological identification of Aspergillus species from the soil of Larkana District (Sindh, Pakistan). - Asian Journal of Agricultural Sciences 1(105): e17.

[4] Ahmad, M. (2017): Community based ecological restoration of Changa Manga forest, Punjab, Pakistan. - Master's thesis, Norwegian University of Life Sciences, Ås.

[5] Ali-Shtayeh, M. S., Mara'i, A. B. B., Jamous, R. M. (2003): Distribution, occurrence and characterization of entomopathogenic fungi in agricultural soil in the Palestinian area. Mycopathologia 156(3): 235-244.

[6] Araujo, J. P., Hughes, D. P. (2016): Diversity of entomopathogenic fungi: which groups conquered the insect body? - Advances in Genetics 94: 1-39.

[7] Bawin, T., Seye, S., Boukraa, J. Y., Zimmer, F. N., Raharimalala, Q., Francis, F. (2016): Production of two entomopathogenic Aspergillus species and insecticidal activity against the mosquito Culex quinquefasciatus compared to Metarhizium anisopliae. - Biocontrol Science and Technology 26(5): 617-629.

[8] Bennett, J. W. (2010): An overview of the genus Aspergillus. - Molecular Biology and Genomics 1-17.

[9] Cray, J. A., Bell, P., Bhaganna, A. Y., Mswaka, D. J., Timsonand, J. E. (2013): The biology of habitat dominance. Can microbes behave as weeds? - Microbial Biotechnology 6: 453-492.

[10] Devarajan, N., Kim, M. (2018): Aspergillus terreus (Trichocomaceae): A natural, ecofriendly mycoinsecticide for control of malaria, filariasis and dengue vectors and its toxicity assessment against an aquatic model organism Artemia nauplii. - Frontiers in Pharmacology 9: 1355-1357. 
[11] Edgar, R. C. (2004): MUSCLE: multiple sequence alignment with high accuracy and high throughput. - Nucleic Acids Research 32: 1792-1797.

[12] Embley, T. M., Finlay, B. J., Thomas, R. H., Dyal, P. L. (1992): The use of rRNA sequences and fluorescent probes to investigate the phylogenetic positions of the anaerobic ciliate Metopus palaeformis and its archaeobacterial endosymbiont. - Journal of General Microbiology 138: 1479-1487.

[13] Guinea, J., M., Sandoval-Denis, P. E., Pelaez, T. (2015): Aspergillus citrinoterreus, a new species of the section Terrei isolated from samples of patients with nonhematological predisposing conditions. - Journal of Clinical Microbiology 53: 611-617.

[14] Haack, M. B., Olsson, L., Hansen, K., Lantz, A. E. (2006): Change in hyphal morphology of Aspergillus oryzae during fed-batch cultivation. - Applied Microbiology and Biotechnology 70(4): 482-487.

[15] Jukes, T. H., Cantor, C. R. (1969): Evolution of Protein Molecules. - Academic Press, New York, pp: 21-132.

[16] Kaur, M., Chadha, P., Kaur, S., Kaur, A., Kaur, R., Yadav, A. K., Kaur, R. (2019): Evaluation of genotoxic and cytotoxic effects of ethyl acetate extract of Aspergillus flavus on Spodoptera litura. - Journal of Applied Microbiology 126(3): 881-893.

[17] Klich, M. A. (2002): Identification of Common Aspergillus Species. - Centraal Bureau voor Schimmelcultures, Utrecht.

[18] Krijgsheld, P., Bleichrodt, R. V., Van Veluw, G. J., Wang, F., Muller, W. H., Dijksterhuis, J., Wosten, H. A. B (2013): Development in Aspergillus. - Studies in Mycology 74: 1-29.

[19] Lage de Moraes, A. M., Lara da Costa, G., Ziccardi de Camargo, B. M., Lourenço de, R., Cunha de Oliveira, P. (2001): The entomopathogenic potential of Aspergillus spp. in mosquitoes vectors of tropical diseases. - Journal of Basic Microbiology: An International Journal on Biochemistry, Physiology, Genetics, Morphology, and Ecology of Microorganisms 41(1): 45-49.

[20] Matsuura, S., Miyazima, S. (1993): Colony of the fungus Aspergillus oryzae and self affine fractal geometry of growth fronts. - Fractals 1(01): 11-19.

[21] Meyling, N. V., Eilenberg, J. (2006): Occurrence and distribution of soil-borne entomopathogenic fungi within a single organic agroecosystem. - Agriculture, Ecosystems and Environment 113: 336-341.

[22] Meyling, N. V., Eilenberg, J. (2007): Ecology of the entomopathogenic fungi Beauveria bassiana and Metarhizium anisopliae in temperate agro ecosystems: potential for conservation biological control. - Biological Control 43(2): 145-155.

[23] Nnakumusana, E. S. (1985): Laboratory infection of mosquito larvae by entomopathogenic fungi with particular reference to Aspergillus parasiticus and its effects on fecundity and longevity of mosquitoes exposed to conidial infections in larval stages. - Current Science 54(23): 1221-1228.

[24] Samson, R. A., Hong, S. B., Frisvad, J. C. (2006): Old and new concepts of species differentiation in Aspergillus. - Medical Mycology 44: S133-S148.

[25] Nnakumusana, E. S. (1985): Laboratory infection of mosquito larvae by entomopathogenic fungi with particular reference to Aspergillus parasiticus and its effects on fecundity and longevity of mosquitoes exposed to conidial infections in larval stages. - Current Science1221-1228.

[26] Tamura, K., Stecher, G., Peterson, D., Filipski, A., Kumar, S. (2011): MEGA6: molecular evolutionary genetics analysis version 6.0. - Molecular Biology and Evolution 30(12): 2725-2729.

[27] Varga, J., Frisvad, J. C., Samson, R. A. (2011): Two new aflatoxin producing species and an overview of Aspergillus section flavi. - Studies in Mycology 69: 57-80.

[28] Wakil, W., Ghazanfar, M. U., Yasin, M. (2014): Naturally occurring entomopathogenic fungi infecting stored grain insect species in Punjab, Pakistan. - Journal of Insect Sciences 14(82): 2-7. 


$$
\text { - } 3804 \text { - }
$$

[29] Yang, Y., Zhang, Y., Wang, M., Li, S. S., Ma, X. Y., Xu, Z. H. (2015): Bioefficacy of entomopathogenic Aspergillus strains against the melon fly, Bactrocera cucurbitae (Diptera: Tephritidae). - Applied Entomology and Zoology 50(4): 443-449.

[30] Ye, M., Lin, Y., Huang, W., Wei, J. (2014): Comparative analysis of Aspergillus oryzae with normal and abnormal color conidia. - Indian Journal of Microbiology 54(1): 108110.

[31] Zhang, P., You, Y., Song, Y., Wang, Y., Zhang, L. (2015): First record of Aspergillus oryzae (Eurotiales: Trichocomaceae) as an entomopathogenic fungus of the locust, Locusta migratoria (Orthoptera: Acrididae). - Biocontrol Science and Technology 25(11): $1285-1298$ 